\title{
Avoiding bias in medical ethical decision-making. Lessons to be learnt from psychology research
}

\author{
Heidi Albisser Schleger • Nicole R. Oehninger • \\ Stella Reiter-Theil
}

Published online: 21 July 2010

(C) Springer Science+Business Media B.V. 2010

\begin{abstract}
When ethical decisions have to be taken in critical, complex medical situations, they often involve decisions that set the course for or against life-sustaining treatments. Therefore the decisions have far-reaching consequences for the patients, their relatives, and often for the clinical staff. Although the rich psychology literature provides evidence that reasoning may be affected by undesired influences that may undermine the quality of the decision outcome, not much attention has been given to this phenomenon in health care or ethics consultation. In this paper, we aim to contribute to the sensitization of the problem of systematic reasoning biases by showing how exemplary individual and group biases can affect the quality of decision-making on an individual and group level. We are addressing clinical ethicists as well as clinicians who guide complex decision-making processes of ethical significance. Knowledge regarding exemplary group psychological biases (e.g. conformity bias), and individual biases (e.g. stereotypes), will be taken from the disciplines of social psychology and cognitive decision science and considered in the field of ethical decisionmaking. Finally we discuss the influence of intuitive versus analytical (systematical) reasoning on the validity of ethical decision-making.
\end{abstract}

Keywords Ethical judgment - Decision-making · Treatment decisions - Clinical ethics consultation . Quality improvement · Bias · Reasoning error

H. Albisser Schleger $(\bowtie) \cdot$ N. R. Oehninger $\cdot$ S. Reiter-Theil Department for Medical and Health Ethics, Medical Faculty, University Hospital Basel, Basel, Switzerland

e-mail: heidi.albisser@unibas.ch

\section{Introduction: reflecting on the origins of misjudgment}

The susceptibility to undesirable influences in medical decision-making — and the ensuing misjudgment or errorhas been studied more thoroughly with regard to patients than with regard to health care professionals. One paramount example regarding treatment is the Placebo Effect and its consequences (Beecher 1955; Brody 1997). In human experimentation, the Rosenthal Effect, also called 'experimenter expectancy effect', that holds that the subject's responses can be influenced through the study leader's expectations, has been acknowledged as an influential factor (Rosenthal 1966). Is there a need for health care professionals to also reflect on their own susceptibility, especially in ethically sensitive situations? We argue that there is evidence for such a need, will show why this is the case, and suggest what should be taken into consideration.

The ethical significance of making treatment decisions, especially in severely ill and vulnerable patients, has received increasing acknowledgement among health care professionals. This awareness can be seen as one factor that has paved the way for the development of clinical ethics support services in the last two decades (American Society for Bioethics and Humanities, ASBH 1998). Research in medical ethics may include, according to Sugarman and Sulmasy (2001), decision analysis as a field of academic inquiry (Asch 2001). Analyzing treatment decisions and their inherent risk of bias, misjudgment, or fallacy, may benefit from research conducted in psychology on imperfect reasoning and the risk of making errors. The discourse on the methodology of ethics or meta-ethics has so far primarily focused on the challenge of avoiding the isought fallacy (Hume 1978; Moore 1959). Sugarman and Sulmasy (2001) list however several other types of fallacy, such as concluding moral validity from majority votes, or 
the derivation of moral judgment from historical facts. Taking quality improvement seriously, we ought to try to improve decision-making and clinical ethics support by understanding and avoiding psychological influences that diminish our capacity for appropriate reasoning.

Psychology research has been instrumental in highlighting specific errors, fallacies and mistakes. It also sheds light on the characteristics of situations and persons or groups that may trigger bias in making judgments and decisions. One of the most prominent discoveries has been the Halo Effect that holds that aspects of the general impression of a person (such as attractiveness), dominates judgment on details such as the person's intellectual capacity (Thorndike 1920). Moral reasoning and judgment has been the subject of sophisticated psychological investigation for two decades; the research of Lawrence Kohlberg, Carol Gilligan and others have stimulated the ethics discourse and contributed to sharpening our view on well argued and balanced moral deliberation (Kohlberg et al. 1983; Nunner-Winkler 1984). The work of John Rawls (1971) and other moral philosophers, especially in discourse ethics (Habermas 1995), have brought a move towards models of reflection and communication that can help to identify and overcome problematic forms of reasoning and conversation.

In clinical ethics support services, the topic of errors and mistakes has been addressed in a textbook edited by Rubin and Zoloth (2000). The quality of ethics consultations and their challenges are discussed and illustrated by case studies (Rubin and Zoloth 2000; Bernal 2000; Reitemeier 2000; Fletcher et al. 2000). Nevertheless, more research is necessary to find out how we can systematically clean our decisions and consultations from reasoning errors that may go unnoticed. Especially studies that evaluate clinical ethics consultation should address the issue of the prevalence of bias, misjudgment or fallacy on the quality of reasoning and decision-making (Foerde et al. 2008; Pfaefflin et al. 2009). Also clinical situations that are characterized by complexity and uniqueness require particular sensitivity and competence regarding ethical issues; they carry a risk of stimulating inappropriate reasoning and communication due to 'natural' dispositions that may be disclosed by applying the findings of psychological research.

Explicit clinical ethical decision-making in critical and complex medical situations often involves decisions regarding continuing or ceasing a life-sustaining treatment. Such decisions have far-reaching consequences for patients and their relatives as well as for the clinical staff. Therefore the quality of the decision is particularly important. In order to assure quality, such decisions are usually discussed as part of an inter-professional, clinical ethics case discussion, moral case deliberation, or clinical ethics consultation
(Molewijk et al. 2008; Reiter-Theil 2009). Both experience and practice reports show that decision processes may be affected or biased both on the team level as well as on the individual level (e.g. Rubin and Zoloth 2000). This paper aims at making a contribution to the field of clinical decision-making and ethics support services in order to better understand and avoid these processes, and to formulate recommendations for good practice. We argue on the basis of a comprehensive understanding of clinical ethics support including more informal rounds; routine rounds where an ethical issue arises; as well as a full ethics consultation that has been requested to solve a specific problem. By addressing clinical ethicists as well as clinicians who are leading or participating in ethics case discussions, we want to sensitize the reader to these issues, and suggest a way to control systematic biases in decision-making.

Our work relies on interdisciplinary competencies including clinical ethics consultation, quality improvement, psychology, and nursing. In the first section, relevant selected findings on systematic decision biases from the descriptive socio-psychological approach and the cognitive decision science will be discussed. The focus will be on examples of systematic inadequacy with group and individual decisions, and their application to clinical ethical decision situations. The second section discusses intuitive versus analytical decision strategies, and their influence on the clinical ethical decision-making process.

\section{Systematic reasoning errors}

The need for ethical reflection in decision-making usually arises in complex situations, typically involves a large amount of diverse, interconnected types of information, and will have to cope with missing data as well as ambiguities. The decision-making situation may be dynamic and nontransparent, and be dependent on changes in the patient's condition, uncertain prognosis, and undesired or uncontrollable effects. Such decisions sometimes need to be made under time pressure, with some of the consequences being irreversible.

Psychological research has shown that in such complex, interconnected, dynamic decision situations, our brain is susceptible to 'reasoning errors' (e.g. Dörner 1997; Jungermann et al. 2005, p. 281). Systematic, i.e. nonaccidental reasoning errors (Redelmeier et al. 2001), happen repeatedly with most people. However identifying and controlling reasoning biases in ethical decision-making process is rarely named as a step in models of ethical decision-making. Clinical ethical decision-making takes place at the individual and at the group level. Therefore the exemplary biases dealt with below (that have been taken from the disciplines of social psychology and cognitive 
decision science), will take examples from both the individual and group level. The following considers the role of the selected biases within ethical decision-making processes at the individual and at the group level.

\section{Examples of systematic reasoning errors in group decision-making processes}

'Process loss': tendency of groups to concentrate on what the majority of members know

The aspects of group interaction that inhibit optimal decision-making are termed 'process loss' in social psychology. In any group, members share a certain amount of information. However, there are always pieces of information not known to everyone.

Strasser und Titus (1985) developed a research paradigm to investigate the effects of shared and non-shared information on group decisions. The paradigm is based on the so-called 'Hidden-Profile-Technique', and the underlying findings of the 'Collective Information Sampling' (Gigone and Hastie 1993, 1996). Using the 'HiddenProfile-Technique' the individual group members are only given access to a fragment of the total information, and therefore the best decision option is not accessible i.e. it is hidden. Groups tend to concentrate on information known to the majority, so called shared information (Stasser and Titus 1985), while ignoring specific information known only to a minority - so called unshared information (see also Kelly and Karau 1999). Shared information appears within the group discussion to be more plausible and it will be consensually validated (Parks and Cowlin 1996).

The influence of unshared information on the ethical decision-making process is discussed in the following sections.

\section{Analysis and conclusion for practice}

Clinical ethical questions cannot be resolved based solely on shared, means medical knowledge. It is of fundamental importance to also include non-shared information, as ethical, legal and psychological aspects, as well as the patient's values. Knowledge from these areas often involves unshared information. If a team fails to share knowledge and to communicate during a case discussion regarding, for example, the patient's wishes, potentially relevant information will not be considered.

The tendency of groups to ignore information that is known only to some can be overcome by clarifying what kinds of information are regarded as relevant, and who is responsible for contributing a certain type of information. We recommend that clinical teams as well as ethical case rounds establish rules for daily routine on how to exchange and record patient-relevant information that otherwise may go unshared, thereby making it transparent to others. Enough time should be allocated for ethical case discussions in order to facilitate exchanging and considering previously unshared information because information that is not known to all members of the clinical team is likely only to be mentioned during the course of a longer case discussion (Larson et al. 1998; Stasser 2000).

Are group decisions always better than individual decisions?

The question whether group decisions lead to better decision outcomes than individual decisions depends on certain variables. One very crucial variable is the availability of (additional) information to certain group members (SchulzHardt et al. 2006). Unless members share their individual knowledge, the quality of group decisions is not superior to decisions taken by knowledgeable and responsible individuals (or even very small teams of two or three). This seems to support forms of clinical ethics support services following the 'consultant' or 'liaison' models (Reiter-Theil 2001, 2003, 2009; Richter 2007).

\section{'Group think'}

Another reason for suboptimal group decisions is so-called 'group think'. This term, coined by Janis (1982), is defined as a quick and simple decision-making method which people use when working in a very cohesive subgroup. A 'cohesive subgroup' means a relatively close-knit team that frequently arises in the clinical setting, e.g. a health care team intensely engaged in caring for a severely ill patient. However, group think may also appear in discussions between renowned experts. 'Group think' is characterized by striving for agreement in a way that hinders group members from evaluating differing or diverging views or courses of action. This may result in values such as harmony or solidarity inappropriately guiding decision-making. Although harmony and especially solidarity are highly esteemed values, following them without reflection may compromise ethical reasoning, and eventually lead to simplistic agreement (Ross et al. 2006).

\section{Analysis and conclusion for practice}

It cannot be made clear enough that in spite of consensusbuilding, good intentions, and even the application of apparently sound reasoning, decision-making processes influenced by unconsidered group think can result in ethically inappropriate decisions. In order to reduce the occurrence of group think when dealing with complex 
ethical decisions, it is recommended that explicit decision procedures or methods be used for reflection and structuring (Agich 2001; Reiter-Theil 2009). Another strategy is to assign the role of a moderator to an adequately trained staff to help integrate various opinions into the case discussion. The moderator could and should counteract group think, in addition to encouraging and facilitating exchange of knowledge and different views; this will be even easier if he or she is not part of the health care team, and therefore less susceptible.

Group size and tendency to conform in groups

Psychological research reveals that pressure to conform in a decision-making process increases with the size of a group (Campbell and Fairey 1989; Gerard et al. 1968; Rosenberg 1961; Saks 1977; Saks and Marti 1997).

\section{Analysis and conclusion for practice}

Discussions of ethically sensitive treatment decisions often occur in an interactive situation with the aim of reaching a well reasoned, justified consensus. Such discussion groups varies in size and setting depending on the urgency and complexity of the decision. Up to a number of four to five people groups show a tendency to produce a pressure to conform (Asch 1956). These group decisions carry a risk for premature agreement. Premature agreement can be counteracted by consciously integrating "unshared information' in the decision-making process. All members, but particularly the moderator or ethics consultant, have the responsibility to reflect, check, or even question an emerging 'consensus' to avoid mere conformity. This is particularly important in societal contexts that prioritize a culture of consensus-building or strongly support the willingness to agree or compromise.

\section{Social impact theory}

Social Impact Theory involves 'informative social influence' as well as 'normative social influence'. 'Informative social influence' is present when a person does not know how to do or express something correctly. Consequently the behavior of others is referred to as an important source of information for selecting appropriate actions for oneself. As this kind of reaction is typically prevalent in unknown, confusing situations, or when the consequences of one's behavior are difficult to anticipate, the effect can be significant when making critical treatment decisions under conditions of uncertainty. In these situations, experts are particularly influential, because they appear to have the most knowledge and experiences concerning what reactions are appropriate (Kelley 1955).
'Normative social influence' means that an individual changes his or her own behavior to adapt to another person or group, not however because of the others' superiority in judging the situation, but rather because the individual wants to be accepted and integrated in the group; benefit from in-group advantages, and avoid being criticized or rejected. This happens through adapting to the social norms, implicit and explicit rules or values and attitudes of the group. Normative social influence can occur even in situations where people conform despite knowing that the action is wrong, as has been shown in prominent psychological experimentation (Asch 1956; Milgram 1976, 1974).

\section{Analysis and conclusion for practice}

To give an example: in an institution of long-term care there is a well established, implicit social norm that it is morally acceptable to restrain a restless or confused patient for medical reasons. Thus a hemiplegic patient's non-paralyzed arm is restrained during the night in order to prevent her from repeatedly pulling out the nasogastric feeding tube. A new young nurse P. joins the care team; he feels that this practice violates the patient's integrity. P. finds himself confronted with uncertainty: whether to speak out and risk infringing group norms, or to follow normative social influence?

If nurse P. decides to comply with the group norm, he misses the chance to raise the ethical question whether or not the restriction of the patient is justified and, if so, for what reasons. Furthermore, the opportunity to clarify the practice in the light of relevant ethics guidelines will also be missed. Instead, mutual trust and an open group climate should be created to enhance reflection and articulation of ethical values and norms of all involved in order to prevent inappropriate treatment decisions.

\section{Examples of systematic biases in individual decision-making processes}

The following section describes relevant selected examples of systematic biases in individual decision-making, which might lead to a suboptimal or biased result.

\section{Belief in a just world}

The 'belief in a just world' bias is based on the dangerous assumption that everyone gets what they deserve, and everyone deserves what they get. Belief in a just world may be applied to oneself or others, consciously or unconsciously (Bierhoff 2006). The belief in a just world does not necessarily hamper judgment processes, but it increases 
the risk of making bad decisions if applied without reflection. People who believe in a just world sympathize with the winners and devalue the losers (Lerner 1980).

\section{Analysis and conclusion for practice}

If health care professionals adopt a 'just world' position, they could believe that patients 'deserve' their medical problems because of their own behavior. This may trigger an attitude that serves to rationalize and support discrimination (e.g. Hurst et al. 2007; Albisser Schleger and ReiterTheil 2007).

\section{Clinical example for the 'Belief-in-a-Just-World Bias'}

An example is the case of a female, obese welfare aid recipient with a slightly low IQ, arteriosclerosis and consequential apoplexia with hemiplegia and speech disorder, with the assumption being made that the problems are caused by immoderate eating behaviour. The assessment of this situation based on a 'Belief in a Just World' would argue that her situation is self-inflicted and, thus, "deserved" as it is; accordingly, it would appear justifiable to delay allocating her a place in a rehabilitation clinic. However a more careful assessment of the situation would disclose that the patient suffered from severe meningitis in her youth, which has resulted in a binge eating disorder ${ }^{1}$ for which she should not be blamed. Furthermore, the patient has multiple risk factors for discrimination (e.g. multimorbidity, chronic illness, low socio-economic status), that can lead to difficulties in obtaining a treatment place in a rehabilitation clinic (Hurst et al. 2007).

Stereotypes, prejudice

Research has shown that stereotypes and prejudice represent subgroups of opinions and attitudes. Prejudices (such as 'old people are obstinate'), involve per definition emotional components that are mistaken, premature, generalizing and clichéd. Prejudices are characterized by their stability and resistance to change, even in the light of contradicting information. Stereotypes (such as 'old people have bad health'), are oversimplified cognitive representations of the social environment, enabling quick processing of information and orientation. Both stereotypes and prejudices lead to information not being critically questioned, and to information that contradicts accepted notions not being appropriately considered in the decision-making process.

\footnotetext{
${ }^{1}$ Binge eating disorder is characterized by compulsive overeating in which people consume huge amounts of food while feeling out of control and powerless to stop.
}

\section{Analysis and conclusion for practice}

Stereotypes and prejudices often have ethical connotations. If they are introduced into the treatment decision-process without reflection in the context of a complex clinical ethical question, stereotypes and prejudices may lead to inappropriate decisions.

\section{Example}

A young man forgets to buy bread at the shop, old persons do not buy bread because they are senile.

\section{Omission bias}

The omission bias describes the subjective perception that it is more risky to act than to omit (with omission meaning non-action, prolonging the present state or avoid a decision). The tendency not to act if the action's consequences are uncertain seems to be due to the wide-spread feeling that one is more culpable for the (potentially negative) consequences of one's actions, than for the same consequences that would result from an omission (Anderson 2003).

\section{Analysis and conclusion for practice}

In medical practice, the psychological phenomenon of the omission bias has been observed by Spranca et al. (1991), and discussed from an ethical perspective, particularly in situations with high uncertainty such as in intensive care (Beck et al. 2008). According to this study, some intensive care doctors were more likely to choose the passive way of 'non-action' or maintaining the present state when confronted with complex or uncertain decision situations, such as whether to limit a life-sustaining measure in a severely ill patient. Preferring non-action means that no active measures will be taken, or that ongoing treatment will be continued without reflection. This tendency appears to be further supported through the rule 'above all, do no harm', which can be interpreted as prioritizing risk avoidance, and as a result may be used to justify non-action or prolongation of the present state. Furthermore, fear of harming the patient through taking action (e.g. legal claims), leads to a preference for omission (Beck et al. 2008). As a result, suffering may be prolonged by continuing treatment (Aberegg et al. 2005; Albisser Schleger et al. 2008; Zikmund-Fisher et al. 2006; Beck et al. 2008).

The omission bias and the related emotions can be counteracted if clinical experts consciously base their decision on facts and commit to respect the patient's wishes as far as possible, while involving the relatives in an appropriate way (Reiter-Theil et al. 2007). 


\section{Intuitive versus analytical decision strategies and their influence on the validity of making ethically sensitive decisions}

Ethically sensitive decisions are often complex, and optimally require systematic reflection in the form of applying a 'balancing of interest process ${ }^{2}$ 'to the various options that are available for action. The choice of the cognitive reasoning strategy-intuitive (automatic, non-reflected) versus analytical (conscious, controlled) - seems to play a role in influencing the quality validity of the ethical decision-making.

\section{Intuitive reasoning}

In everyday decision situations, information processing within the decision-making process tends to occur in a resource-saving way, with the resource 'reasoning' being used as sparingly as possible. This typically implies using intuitive, automatic, unconscious or fast decision strategies, which lead to a decision relying on a few distinct, situational features, whereby the deeper reflection of the consequences of the possible treatment options are explicitly ignored. One approach for such a fast (and therefore resource-saving) information processing is 'heuristics', socalled rules of thumb that provide a quick orientation and simple answers. Heuristics speed up the ability to decide by simplifying the problem. In everyday decision situations, they can usefully lead to quick as well as efficient outcomes (e.g. Gigerenzer et al. 1999; Hertwig and Todd 2003). However, empirical literature on the validity of moral heuristics is scarce (Sunstein 2005), and controversial.

We consider that intuitive reasoning can play a role in identifying typically problematic situations. However in ethical decision-making processes, what is usually required is an explicit identification and evaluation of the consequences of the various options for action. The decision and recommendation regarding which option is ethically justifiable and preferable should be based on an analytical reasoning strategy.

\footnotetext{
${ }^{2}$ Balancing of interest' is a method developed in the discipline of ethics. It describes the process of practical reasoning needed for a qualified solution to a choice or decision conflict. Such conflicts arise because a specific decision may be beneficial for one person or group, but detrimental for another person or group. In such cases, the expected benefits and burdens must be weighed as carefully as possible, while taking into account individual and collective needs in addition to their urgency; the rights of the individual; precedence of public welfare, and questions of justice.
}

Analytical reasoning

The analytical reasoning strategy is characterized inter alia by a consciously controlled decision process that minimizes automaticity, resulting in the emotional influence on the decision process being fairly low. The decision speed is slow because of the high number of details that need to be considered. Such analytical decision strategies are characterized by good predictive power, high reliability and high probability that the decision will be based on the best available scientific literature. Table 1 summarizes and contrasts the features of intuitive versus analytical decision strategies.

\section{Analysis and conclusion for practice}

Lack of time is a dominating phenomenon that most health care professionals face in clinical practice. If time-saving, intuitive decision strategies are applied uncritically to complex, anomalous ethically sensitive decision situations, there is a risk of systematic bias occurring, thus violating ethical values and norms. Therefore in ethical decisionmaking, the appropriate cognitive strategy should be consciously selected.

\section{Conclusions}

In this paper we aim to contribute to the sensitization of systematic reasoning biases. Whereas formal and particularly informal fallacies are mostly addressed by philosophy and logic, our contribution compliments these strands of analysis by focusing on empirical research and decision psychology because we consider these disciplines to be valuable in this field of enquiry.

Possible risk factors for systematic biases include undesired, latent influencing factors on individual or group decision-making processes, as well as the reasoning strategy (intuitive vs. analytical) underlying the decision. Therefore, an awareness of potential reasoning errors is needed. A critical reflection of information processing supports the awareness of latent influencing factors on complex clinical ethical decision-making processes from a meta-perspective. Acknowledging one's own error-proneness is a prerequisite to the prevention of systematic reasoning errors.

Explicit decision-making strategies or methods including check lists are possible approaches for the control of systematic biases. They are not just mnemonic devices, but precautionary measures against 'reasoning ergonomics' that may challenge the quality of the outcome.

The recent literature on clinical decision-making and the ethics support reflects the need for a thorough discourse on 
Table 1 Characteristics of intuitive versus analytical decisions

\begin{tabular}{lll}
\hline & Intuitive & Analytical \\
\hline Cognitive style & $\begin{array}{c}\text { Heuristic (rules of } \\
\text { thumb) } \\
\text { Conscious control of the decision process }\end{array}$ & Systematic \\
Automaticity & Low & High \\
Decision speed & High & Low \\
Decision reliability & Fast & Slow \\
Errors & Low & High \\
& Normal distribution & Few, but \\
Effort & & serious \\
Predictive power & Low & High \\
Influence of emotions on decisions & Low & High \\
Number of details considered for decision-making & High & Low \\
Probability that the decision will be based on the best available & Low & High \\
scientific literature & & High \\
\hline
\end{tabular}

American Society for Bioethics and Humanities (ASBH). 1998. Core competences for health care ethics consultation. Reprinted 2003 Glenview, IL, USA. In Ethics consultation. From theory to practice, ed. M.P. Aulisio, R.M. Arnold, and S.J. Youngner, 165-209. Baltimore and London: The John Hopkins Press.

Anderson, C.J. 2003. The psychology of doing nothing-Forms of decision avoidance result from reason and emotion. Psychological Bulletin 129: 9-167.

Asch, S.E. 1956. Studies of independence and conformity-A minority of one against an unanimous majority. Psychological Monographs 70(9): 416.

Asch, D.A. 2001. Economics and decision science. In Methods in medical ethics, ed. J. Sugarman, and D.P. Sulmasy, 227-234. Washington DC: Georgetown University Press.

Beck, S., A. van de Loo, and S. Reiter-Theil. 2008. A 'little bit illegal'? Withholding and withdrawing of mechanical ventilation in the eyes of German intensive care physicians. Medicine, Health Care and Philosophy 11: 7-16.

Acknowledgments This paper is part of the project "Between Over-Treatment and Under-Treatment: Ethical Problems of MicroAllocation", no. 3200B0-113724/1, funded by the Swiss National Science Foundation. We are grateful for the helpful comments of Prof. Volker Dittmann, Legal and Forensic Medicine, University of Basel. We also thank Marcel Mertz, MA, for his helpful comments. Piera Jones, MA, and Nicola Stingelin Giles, MBA, MAS, MAE gave invaluable help in translating and editing the manuscript into native English. The paper has benefited much from the discussions in the PhD Colloquium, Dept. Medical and Health Ethics, Medical Faculty, University Hospital Basel.

\section{References}

Aberegg, S.K., E.F. Haponik, and P.B. Terry. 2005. Omission bias and decision making in pulmonary and critical care medicine. Chest American College of Chest Physicians 128: 1497-1505.

Agich, G. 2001. The question of method in ethics consultation. The American Journal of Bioethics 1(4): 31-41.

Albisser Schleger, H., and S. Reiter-Theil. 2007. 'Age' and 'Costs'Factors in treatment decisions at the end-of life? An analysis of informal knowledge structures of doctors and nurses. Ethik in der Medizin 19: 103-119.

Albisser Schleger, H., H. Pargger, and S. Reiter-Theil. 2008. 'Futility'-Overtreatment at the end of life? Reasons for missed cessations of therapy in geriatric and critical care. Zeitschrift für Palliativmedizin 9: 67-75.
Beecher, H.K. 1955. The powerful placebo. The Journal of the American Medicine Association 159: 1602-1606.

Bernal, E.W. 2000. Errors in ethics consultation. In Margin of error: The ethics of mistakes in the practice of medicine, ed. S.B. Rubin, and L. Zoloth, 255-272. Hagerstown, Maryland: University Publishing Group.

Bierhoff, H. 2006. Sozialpsychologie-Ein Lehrbuch. Stuttgart: W. Kohlhammer.

Brody, H. 1997. The doctor as therapeutic agent: A placebo research agenda. In The placebo effect-An interdisciplinary exploration, ed. E. Harrington, 77-92. Cambridge: Harvard University Press.

Campbell, J.D., and P.J. Fairey. 1989. Informational and normative routes to conformity-The effect of faction size as a function on norm extremity and attention to the stimulus. Journal of Personality and Social Psychology 57: 457-468.

Croskerry, P. 2005. The theory and practice of clinical decisionmaking. The Canadian Journal of Anasthesia 52(6/pp): R1-R8.

Dörner, D. 1997. The logic of failure: Recognizing and avoiding error in complex situations. Cambridge, MA: Perseus Press.

Fletcher, J., R.J. Boyleand, and E.M. Spencer. 2000. Errors in Healthcare Ethics Consultation. In Margin of error: The ethics of mistakes in the practice of medicine, ed. S.B. Rubin, and L. Zoloth, 343-373. Hagerstown, Maryland: University Publishing Group.

Foerde, R., R. Pedersen, and V. Akre. 2008. Clinicians' evaluation of clinical ethics consultations in Norway: A tool for quality 
improvement. Medicine, Health Care and Philosophy 11(1): $17-25$.

Gerard, H.B., R.A. Wilhelmy, and E.S. Conolley. 1968. Conformity and group size. Journal of Personality and Social Psychology 8: 79-82.

Gigerenzer, G., P.M. Todd, and The ABC Group. 1999. Simple heuristics that make us smart. New York: Oxford University Press.

Gigone, D., and R. Hastie. 1993. The common knowledge effect: Information sharing and group judgment. Journal of Personality and Social Psychology 65: 959-974.

Gigone, D., and R. Hastie. 1996. The impact of information on group judgment: A model and computer simulation. In Understanding group behavior: Consensual action by small groups, Vol. 1, ed. E. Witte, and J.H. Davis, 221-251. Mahwah: Lawrence Erlbaum.

Habermas, J. 1995. Moral consciousness and communicative action. Cambridge, MA: The MIT Press.

Hertwig, R., and P.M. Todd. 2003. More is not always better-The benefits of cognitive limits. In Thinking-Psychological perspectives on reasoning, judgment and decision making, ed. D. Hardman, and L. Macchi, 213-231. Chichester, England: Wiley.

Hume, D. 1978. A treatise of human nature. Clarendon: Oxford University Press.

Hurst, S.A., R. Forde, S. Reiter-Theil, A.M. Slowther, A. Perrier, R. Pegoraro, and M. Danis. 2007. Physicians' views on resource availability and equity in four European health care systems. BMC Health Services Research 7: 137.

Janis, I.L. 1982. Groupthink-Psychological studies of policy decisions and fiascoe, 2nd ed. Boston: Hougthon Mifflin.

Jungermann, H., H.R. Pfister, and K. Fischer. 2005. Die Psychologie der Entscheidung-Eine Einführung. Heidelberg: Spektrum.

Kelley, H.H. 1955. The two functions of reference groups. In Readings in social psychology, ed. G.E. Swanson, T.E. Newcomb, and E.L. Hartley, 410-414. New York: Henry Holt.

Kelly, J.R., and S.J. Karau. 1999. Group decision making-The effects of initial preferences and time pressure. Personality and Social Psychology Bulletin 25: 1342-1354.

Kohlberg, L., C. Levine, and A. Hewer. 1983. Moral stages: A current formulation and a response to critics. Basel: Karger.

Larson, J.R.J., C. Christensen, T.M. Franz, and A.S. Abbott. 1998. Diagnosing groups-The pooling, management, and impact of shared and unshared case information in team-based medical decision making. Journal of Personality and Social Psychology 75: 93-108.

Lerner, M.J. 1980. The belief in a just world-A fundamental delusion. New York: Plenum.

Milgram, S. 1974. Obedience to authority-An experimental view. New York: Harper \& Row.

Milgram, S. 1976. Obedience to criminal orders-The compulsion to do evil. In Contemporary social psychology-Representative readings, ed. T. Blass, 175-184. Itasca: Peacock.

Molewijk, B., M. Verkerk, H. Milius, and G. Widdershoven. 2008. Implementing moral case deliberation in a psychiatric hospital: Process and outcome. Medicine, Health Care and Philosophy 11(1): 43-56.

Moore, G.E. 1959. Principia ethica. Cambridge: Cambridge University Press.

Nunner-Winkler, G. 1984. Two Moralities? A Critical Discussion of an Ethic of Care and Responsibility versus an Ethic of Rights and Justice. In Morality, moral behavior, and moral development, ed. W.M. Kurtines, and J.L. Gewirtz. New York: Wiley.

Parks, C.D., and R.A. Cowlin. 1996. Acceptance of uncommon information into group discussion when that information is or is not demonstrable. Organizational Behavior and Human Decision Processes 66(3): 307-315.

Pfaefflin, M., K. Kobert, and S. Reiter-Theil. 2009. Evaluating clinical ethics consultation. Cambridge Quarterly Healthcare Ethics 18(4): 406-419.
Rawls, J. 1971. A theory of justice. Cambridge, MA: Belknap Press of Harvard University Press.

Redelmeier, D.A., L.E. Ferris, J.V. Tu, J.E. Hux, and M.J. Schull. 2001. Problems for clinical judgement-Introducing cognitive psychology as one more basic science. Journal of Applied Mathematics and Computing 164(3): 358-360.

Reitemeier, P.J. 2000. Quality and error in bioethics consultation: A puzzle in pieces. In Margin of error: The ethics of mistakes in the practice of medicine, ed. S.B. Rubin, and L. Zoloth, 231-253. Hagerstown, Maryland: University Publishing Group.

Reiter-Theil, S. 2001. Ethics consultation in Germany: The present situation. HEC-Forum 13(3): 265-280.

Reiter-Theil, S. 2003. Balancing the Perspectives. The patient's role in clinical ethics consultation. Medicine, Health Care and Philosophy 6: 247-254.

Reiter-Theil, S. 2009. Dealing with the normative dimension in clinical ethics consultation. Cambridge Quarterly Healthcare Ethics 18(4): 347-359.

Reiter-Theil, S., M. Mertz, and B. Meyer-Zehnder. 2007. The complex Role of Relatives in end-of-life decision-making: An ethical analysis. HEC-Forum 19(4): 341-364.

Richter, G. 2007. Greater patient, family and surrogate involvement in clinical ethics consultation: The model of clinical ethics liaison as a measure for preventive ethics. HEC-Forum 19(4): 327-340.

Rosenberg, L.A. 1961. Group size, prior experience and conformity. Journal of Abnormal and Social Psychology 63: 436-437.

Rosenthal, R. 1966. Experimenter effects in behavioral research. New York: Appleton-Entury-Crofts.

Ross, J., S. Ross, and B. McClung. 2006. Ethical decision making and organizational behavior: A case of life and death. HEC Forum 18: 193-206.

Rubin, S.B., and L. Zoloth (eds.). 2000. Margin of error: The ethics of mistakes in the practice of medicine. Hagerstown, Maryland: University Publishing Group.

Saks, M.J. 1977. Jury verdicts-The role of group size and social decision rule. Lexington MA: Heath.

Saks, M.J., and M.W. Marti. 1997. A meta-analysis of the effects of jury size. Law and Human Behavior 21(5): 451-467.

Schulz-Hardt, S., F. Brodbeck, A. Mojzisch, R. Kerschreiter, and D. Frey. 2006. Group decision making in hidden profile situationsDissent as a facilitator for decision quality. Journal of Personality and Social Psychology 6: 1080-1093.

Spranca, M., E. Minsk, and J. Baron. 1991. Omission and commission in judgment and choice. Journal of Experimental Social Psychology 27(1): 76-105.

Stasser, G. 2000. Information distribution, participation and group decision-Explorations with the DISCUSS and SPEAK models. In Computational modelling of behaviour in organizations, ed. D.R. Ilgen, and C.L. Hulin, 135-161. Washington, DC: American Psychological Association.

Stasser, G., and W. Titus. 1985. Pooling of unshared information in group decision making-Biased information sampling during discussion. Journal of Personality and Social Psychology 48: 1467-1478.

Sugarman, J., and D.P. Sulmasy (eds.). 2001. Methods in medical ethics. Washington D.C.: Georgetown University Press.

Sunstein, C.R. 2005. Moral heuristics. Behavioral and Brain Sciences 28(4): $531-573$.

Thorndike, E.L. 1920. A constant error in psychological rating. Journal of Applied Psychology 4: 25-29.

Zikmund-Fisher, B.J., B. Sarr, A. Fagerlin, and P.A. Ubel. 2006. A matter of perspective-Choosing for others differs from choosing for yourself in making treatment decisions. Journal of General Internal Medicine 21(6): 618-622. 